Article

\title{
Synthesis, Characterization, and Antibacterial Activities of High-Valence Silver Propamidine Nanoparticles
}

\author{
Jinran Lee ${ }^{\dagger}$, Baskaran Purushothaman ${ }^{\dagger}$, Zhao Li, Goutam Kulsi and Joon Myong Song * \\ College of Pharmacy, Seoul National University, Seoul 151-742, Korea; sally3008@snu.ac.kr (J.L.); \\ baskaran@snu.ac.kr (B.P.); lizhao1991@snu.ac.kr (Z.L.); goutam@snu.ac.kr (G.K.) \\ * Correspondence: jmsong@snu.ac.kr; Tel.: +82-2-880-7841 \\ + These two authors contributed equally to this work.
}

Received: 20 June 2017; Accepted: 15 July 2017; Published: 18 July 2017

\begin{abstract}
Diabetic foot ulcer (DFU) is becoming more serious concern as it affects $95 \%$ of diabetic patients worldwide. It has been shown that the Staphylococcus aureus and other Gram-negative microorganisms are the main reasons behind this disease. Though many antibiotics are presently used to treat the DFU, due to increased bacterial resistance, new alternative therapies are always welcome. To address this alarming issue, we have designed and synthesized the high-valence silver propamidine $(\mathrm{Ag}(\mathrm{II}) \mathrm{PRO})$ complex as well as nanoparticles and characterized both by usual spectroscopic methods. The reverse microemulsion technique has been applied to synthesize $\mathrm{Ag}$ (II)PRO nanoparticles and its antibacterial activity has been compared with zero-valence silver nanoparticles (AgNPs) with similar size. The antibacterial efficacies of Ag(II)PRO nanoparticles and AgNPs were tested against Gram-negative and Gram -positive organisms responsible for DFU. The newly synthesized high-valence Ag(II)PRO nanoparticles showed higher antibacterial activity compared to silver-only nanoparticles (AgNPs). This study concludes that the high-valence $\mathrm{Ag}$ (II)PRO nanoparticles show better antibacterial activity than AgNPs and they may serve as the next generation therapeutic agent for the diabetic wound care.
\end{abstract}

Keywords: high-valence silver; nanoparticles; propamidine; diabetic foot ulcer; antibacterial

\section{Introduction}

Diabetic foot ulcer (DFU) is a major complication in patients with diabetic mellitus and causes substantial morbidity and increases mortality [1,2]. Many patients are admitted in hospitals with DFU and their conditions get fatal when it progresses to life threatening diabetic foot infection (DFI) $[3,4]$. Peripheral vascular disease and diabetic neuropathy are considered the most causative factors in DFU. They can act alone, together, or in combination with other factors such as biomechanical abnormalities, microvascular disease, increased susceptibility to infection, and limited joint mobility. A number of studies have found that Staphylococcus aureus is mostly responsible pathogen for the DFU in the feet of the diabetic patients. From very recent findings, it has been shown that the predominance of Gram-negative aerobes (P. aeruginosa and Acinetobacter sp.) have major role in DFU [5-8].

For many years, AgNPs and its metal complexes have been used extensively as antibacterial and wound healing agent due to their strong antimicrobial activity [9-13]. The bactericidal properties of the AgNPs have major advantages in the preparation of various silver containing topical agents for the treatment of chronic wounds. A variety of wound-healing agents, such as chlorhexidine aqueous solution and silver sulfadiazine cream, are currently being used to treat wounds. The AgNPs experience both shape and size dependent interactions with Gram-negative bacteria. The high surface to volume ratio of nanoparticles ensures that a significantly large surface area of the particles is 
in contact with the bacteria. Several studies have suggested that silver nanoparticles have the potential to treat human cancers, including leukemia [14]. Due to increased bacterial resistance to antibiotics, many diabetic patients do not heal properly. Bacterial resistance to commonly prescribed antibiotics-particularly quinolones (ciprofloxacin) and third generation cephalosporin (cefotaxime, ceftriaxone)-was noticeable for the treatment of infected DFU [15]. High-valence silver nanoparticles are now considered as a possible substitute to antibiotics and appear to have a higher antimicrobial activity. It is also used to solve the problem of the emergence of bacterial multidrug resistance [16,17]. Recently, K. Yang et al. synthesized the high-valence silver salt bis(hydrogen periodato)argentite(III) complex and investigated the wound healing and antibacterial efficacy against S. aureus and P. aeruginosa [18]. Our previous reports also suggested that high-valence silver nanoparticles showed stronger antibacterial activity than low-valence silver nanoparticles [19-22]. Encouraged by these findings we thought to produce high-valence silver-based nanoparticles as antibacterial agent which would result in greater antimicrobial effectiveness against antibiotic resistant organisms. Silver metal exhibits in three oxidation states $+1,+2$, and +3 and can form complexes with suitable ligands. In this work, we attempted to synthesize high-valance nanosized Ag(II)PRO complex for higher antibacterial activity. Both AgNPs and Ag(II)PRO nanoparticles were synthesized in similar size and their antibacterial properties were compared.

An aromatic diamidine compound propamidine is active against a number of protozoal organisms can inhibit the growth of bacteria in wounds. The antibacterial activity of propamidine was first reported in 1943 by W. R. Thrower et al. and used for the treatment of Acanthamoeba keratitis and other corneal infections [23]. This polydiguanide molecule with silver can form silver polydiguanide complexes which have the potential to be used as a novel class of topical antimicrobial agent, particularly for the treatment of burn and wound infections. Polydiguanides possess conjugate single and double bond systems and filled $p$-type delocalized orbitals suitable for high-valence silver complex formation. It has been shown that the diamidine and guanidine type compounds like brolene and chlorhexidine have been used for the antibacterial and antifungal agents for many years [24-27]. Polyhexamethylene guanidine (PHMG) has a wide acceptability as non-toxic disinfectants or additives. Propamidine $\left(4,4^{\prime}\right.$-(propane-1,3-diylbis(oxy))dibenzimidamide) is called a diamidine derivative because of the two aromatic rings containing urea-type acetimidamide substitution at the fourth position of propamidine. The imine $(=\mathrm{NH})$ groups in the propamidine molecule make the ligand ideal for the donation of electron to the silver metal to form coordination bond. Thus, we have chosen the propamidine as a chelating ligand for the synthesis of high-valence silver(II) complex. In this study, we have designed and synthesized high-valence Ag(II)PRO complex and characterized it by NMR, FT-IR, XPS and mass spectroscopy techniques. After confirming the formation of Ag(II)PRO complex, high-valence Ag(II)PRO nanoparticles were synthesized by reverse microemulsion technique and their antibacterial activity was studied by comparing it with silver-only nanoparticles (AgNPs). The synthesized Ag(II)PRO nanoparticles possess higher antibacterial activities than the AgNPs against the tested Gram-positive/negative strains responsible for DFU. The minimal inhibitory concentrations (MICs) and minimum bacterial concentrations (MBCs) of Ag(II)PRO nanoparticles were much lower than those of the AgNPs. These Ag(II)PRO nanoparticles have the potential to be used as a novel class of topical antimicrobial agent, particularly for the treatment of burn and wound infection.

\section{Materials and Methods}

\subsection{Materials}

Propamidine was purchased from StruChem Co., Ltd., Wujiang, China. Silver nitrate, triethylamine, sodium persulfate, dioctyl sulfosuccinate (AOT), sodium borohydride, sodium citrate, and heptane used for the synthesis of nanoparticles were purchased from Sigma-Aldrich, Yongin, South Korea. The NMR spectra were recorded in DMSO- $d_{6}$ and $\mathrm{D}_{2} \mathrm{O}$ at $25{ }^{\circ} \mathrm{C}$ using a $400 \mathrm{MHz}$ Bruker Avance NMR spectrometer (Bruker Biospin GmbH, Rheinstetten, Germany) and 0.05\% TMS 
was used as an internal standard. FT-IR spectra were recorded in a JASCO FT/IR-4200 spectrometer (JASCO, Hachioji, Japan). The mass spectra were recorded in Agilant 6530 Q-TOF LC-MS (ESI) spectrometer (Agilant Technologies, Santa Clara, CA, USA). TEM was recorded in JEM 3010 and JEM 1010 (Jeol, Tokyo, Japan). The UV-Vis absorption spectra were collected on a Thermo Scientific Evolution 60 instrument (Thermofischer Scientific Inc., Fremont, CA, USA).

\subsection{Synthesis of $A g(I I) P R O$ Complex}

The Ag(II)PRO complex synthesis was performed in methanol: water (3:1) solvent system. 2 mmol of propamidine was first dissolved in methanol/water, followed by slow addition of $1 \mathrm{mmol}$ of silver nitrate solution. The reaction mixture was stirred for $20 \mathrm{~min}$ at $\mathrm{RT}$. Then, the $\mathrm{pH}$ of the reaction medium was adjusted by adding triethylamine. The reaction was stirred at room temperature for $3 \mathrm{~h}$. The complex was formed as solid. Then the solid was filtered and washed with hexane:methanol (1:1) mixture to get pure product. The complex was dried and structure was analyzed by ${ }^{1} \mathrm{H}-\mathrm{NMR}, \mathrm{FT}-\mathrm{IR}$, XPS (Sigma Probe, Thermo-VG, London, UK) and Mass spectroscopy.

\subsection{Characterization of $A g(I I) P R O$ Complex}

For propamidine: IR $\left(v, \mathrm{~cm}^{-1}\right)$ : 3202 and $3104(-\mathrm{NH}), 2348,1663(\mathrm{C}=\mathrm{N}, \mathrm{m})$ and $1604(\mathrm{C}=\mathrm{C})$, 1483(- $\left.\mathrm{CH}_{2}\right) 1258(\mathrm{C}-\mathrm{N}) .{ }^{1} \mathrm{H}-\mathrm{NMR}\left(400 \mathrm{MHz}, \mathrm{DMSO}-d_{6}, \delta\right): 2.23\left(-\mathrm{CH}_{2}\right.$ Proton, $\left.\mathrm{m}\right), 4.27\left(-\mathrm{OCH}_{2}\right.$ proton, dd), $7.17(4 \mathrm{H}, \mathrm{Ar}-\mathrm{H}, \mathrm{m}), 7.86(4 \mathrm{H}, \mathrm{Ar}-\mathrm{H}, \mathrm{m}) .9 .09$ (NH Proton, s), 9.28 (NH proton, s). For Ag(II)PRO: IR $\left(v, \mathrm{~cm}^{-1}\right): 2348(\mathrm{C}-\mathrm{N}, \mathrm{m}), 1606(\mathrm{C}=\mathrm{C}), 1495,1250(\mathrm{C}-\mathrm{N}, \mathrm{m}) .{ }^{1} \mathrm{H}-\mathrm{NMR}\left(400 \mathrm{MHz}, \mathrm{D}_{2} \mathrm{O}, \delta\right): 2.21\left(-\mathrm{CH}_{2}\right.$ proton, $\mathrm{m}), 4.24\left(-\mathrm{OCH}_{2}\right.$ proton, $\left.\mathrm{m}\right), 7.04(\mathrm{Ar}-\mathrm{H}, \mathrm{m}), 7.64(\mathrm{Ar}-\mathrm{H}, \mathrm{m})$. Q-TOF ESI-MS spectrum for $\mathrm{Ag}$ (II)PRO: $\mathrm{C}_{17} \mathrm{H}_{18} \mathrm{AgN}_{4} \mathrm{O}_{2} \mathrm{M}-311$ : 418.97. UV-Vis $\left(\lambda_{\max }\right)=320 \mathrm{~nm}$.

\subsection{Characterization of $A g(I I) P R O$ Complex by X-ray Photoelectron Spectroscopy (XPS)}

The high-valence $\mathrm{Ag}(\mathrm{II}) \mathrm{PRO}$ complex formation was confirmed by XPS spectrum (Sigma Probe, Thermo-VG, London, UK) with a monochromatic Al K $\alpha$ (15 kV, $100 \mathrm{~W}, 400$ micrometer) X-ray source. The XPS data were obtained with a pass energy of $20 \mathrm{eV}$ and a step size of $0.1 \mathrm{eV}$ for narrow scan.

\subsection{Synthesis of High-Valence Ag(II)PRO Nanoparticles}

Nanoparticles of $\mathrm{Ag}(\mathrm{II}) \mathrm{PRO}$ complex were synthesized using water in oil microemulsion technique. Briefly, the synthesis of nanoparticles was performed by dissolving AOT $(0.44 \mathrm{~g}, 0.1 \mathrm{M})$ in $10 \mathrm{~mL}$ of heptane and followed by addition of $90 \mu \mathrm{L}$ aqueous solution of propamidine. To overcome the solubility issue of the propamidine, we have added dilute sulfuric acid. Subsequently, $90 \mu \mathrm{L}$ of silver nitrate and $90 \mu \mathrm{L}$ of sodium persulfate were added to the heptane solution. The reaction mixture was stirred at $\mathrm{RT}$ for $15 \mathrm{~min}$ to get homogenized solution. Then, the $\mathrm{pH}$ of the reaction mixture was adjusted by adding triethylamine to form a stable microemulsion $(\mathrm{pH}=7.0)$. In this reaction mixture, $\mathrm{AgNO}_{3}$, propamidine, and sodium peroxydisulfate were used in 1:2:2 molar ratio to form the complex. The reaction was stirred at room temperature for $1 \mathrm{~h}$. The color of the microemulsion turned brown, indicating the oxidation of silver to a higher valence state. Then stirring was continued for $24 \mathrm{~h}$. Nanoparticles were isolated by breaking the microemulsion system using ethanol and were recovered by centrifugation at 10,000 rpm for $20 \mathrm{~min}$. After centrifugation, the nanoparticles were washed twice with diethylether to remove the unreacted starting materials and surfactants. Finally, $\mathrm{Ag}$ (II)PRO nanoparticles were dried under a vacuum, collected, and stored at room temperature.

\subsection{Synthesis of $A g N P s$}

Silver nanoparticles were synthesized by previously published method [28]. Briefly, $1 \mathrm{mM}$ of $\mathrm{NaBH}_{4}$ and $3.55 \mathrm{mM}$ of sodium citrate aqueous solution were mixed and stirred at $60^{\circ} \mathrm{C}$ for $30 \mathrm{~min}$. Then $2 \mathrm{~mL}$ of $\mathrm{AgNO}_{3}(1 \mathrm{mM})$ was added dropwise to the above reaction mixture, stirring was continued and the temperature was raised to $90^{\circ} \mathrm{C}$. Then the $\mathrm{pH}$ of the mixture was adjusted to 
10.5 using $0.1 \mathrm{M}$ of $\mathrm{NaOH}$. The color of the solution changed to yellow. The solution was cooled to room temperature. Then nanoparticles were centrifuged at 12,000 rpm for $20 \mathrm{~min}$ and collected. The nanoparticles were washed two times with water. The collected AgNPs were characterized by TEM and UV-Vis spectroscopy.

\subsection{Transmission Electron Microscope (TEM) Analysis}

The size and morphology of Ag(II)PRO and AgNPs were measured using transmission electron microscope (JEM 3010 and JEM 1010, Jeol, Tokyo). The TEM sample was prepared by placing a drop of the nanoparticles on 200-mesh carbon-coated copper grids.

\subsection{Bacterial Strain and Culture Conditions}

Three strains of Gram-positive bacteria (Staphylococcus aureus (ATCC 25923), Enterococcus faecalis (ATCC 29212), Streptococcus agalactiae (ATCC 12386)) and Gram-negative bacteria (Pseudomonas aeruginosa (ATCC 27853), Klebsiella pneumonia (ATCC 10031), Acinetobacter calcoaceticus (ATCC 2305)) were used for this study. All bacterial strains were obtained from the Korean culture center of microorganisms (Seoul, South Korea, American Type Culture Collection, Rockville, MD, USA). All tests were performed according to the Clinical and Laboratory Standards Institute (formerly National Committee for Clinical Laboratory Standard, NCCLS) guidelines. The strains were cultured overnight at $37^{\circ} \mathrm{C}$ under aerobic conditions in Muller Hinton broth or agar (MH, Difco Laboratories, Detroit, MI, USA).

\subsection{Determinations of $M I C s$ and $M B C s$}

MICs were determined by the broth dilution method in Mueller Hinton broth (MH, Difco Laboratories, Detroit, MI, USA) for all species, using a multipoint inoculator. Plates were read after incubation at $37^{\circ} \mathrm{C}$ for $24 \mathrm{~h}$ in air for all species. Mueller Hinton broth (MH, Difco Laboratories, Detroit, MI, USA) was used to determine the MICs for all bacterial strains. Strains were cultured in 96-well microplates. To evaluate the inhibitory effects of the antibacterial agents on bacterial growth, each well was supplemented with a range of concentrations of the active agents. Following $24 \mathrm{~h}$ incubation in air or $48 \mathrm{~h}$ incubation in a GasPak ${ }^{\circledR}$ jar system at $37^{\circ} \mathrm{C}$, the wells were inspected for microbial growth, and the MIC was defined as the lowest concentration that did not produce visual growth. An uninoculated set was also incubated to determine any coagulation effect. The minimum bactericidal concentrations (MBCs) were determined by the reinoculation of growth from each well into empty $\mathrm{MH}$ agar or BHI agar plates. After $24 \mathrm{~h}$ or $48 \mathrm{~h}$ of incubation, the MBC was defined as the lowest concentration at which no growth was observed on the plate. All tests were performed in triplicate. Determination of the MIC and the MBC was performed according to the guidelines recommended by the Clinical and Laboratory Standards Institute (CLSI).

\section{Results and Discussion}

\subsection{Synthesis of AgNPs and $A g(I I) P R O$ Nanoparticles}

We have previously reported the synthesis of high-valence silver nanoconjugates with higher antibacterial efficacy $[20,21]$. The polydiguanide type compound chlorhexidine (CHX) possessed two ionizable guanidine moieties which were suitable for the synthesis of stable high-valence silver chlorhexidine (Ag-CHX) complex. The molar ratio 1:1 of chlorhexidine and $\mathrm{AgNO}_{3}$ was used to make $\mathrm{AgCHX}$ complex as the ligand coordinated with four nitrogen donor atoms from two guanidine units. In this present work, propamidine has been used as a new ligand to make stable high-valence nanocrystalline silver complex. The diamidine compound propamidine is similar to guanidine type compound but not exactly the same as chlorhexidine structure. In this study, 2:1 molar ratio of propamidine and $\mathrm{AgNO}_{3}$ is used to form high-valence silver complex as four nitrogen donor atoms are coming from two propamidine units. Particularly, propamidine has diamidine structure, which 
requires 2:1 molar ratio for the complexation between silver ion and propamidne. This approach may contribute to the generalization of synthesis of silver complex grown as silver nanoparticles. The synthetic scheme of high-valence Ag(II)PRO complex has been shown in Figure 1. The synthesis of $\mathrm{Ag}(\mathrm{II}) \mathrm{PRO}$ complex was achieved by different solvent conditions. Initially, equal and different ratios of DMSO, water, and methanol were used to optimize the reaction condition. Finally, the reaction was successfully performed in methanol:water at a 3:1 ratio. After confirming the formation of Ag(II)PRO complex by NMR, FT-IR, mass and XPS spectrum, we synthesized the high-valence $\mathrm{Ag}(\mathrm{II}) \mathrm{PRO}$ nanoparticles by microemulsion technique. Figure 2 shows the synthetic scheme for the synthesis of $\mathrm{Ag}(\mathrm{II}) \mathrm{PRO}$ nanoparticles by microemulsion method.

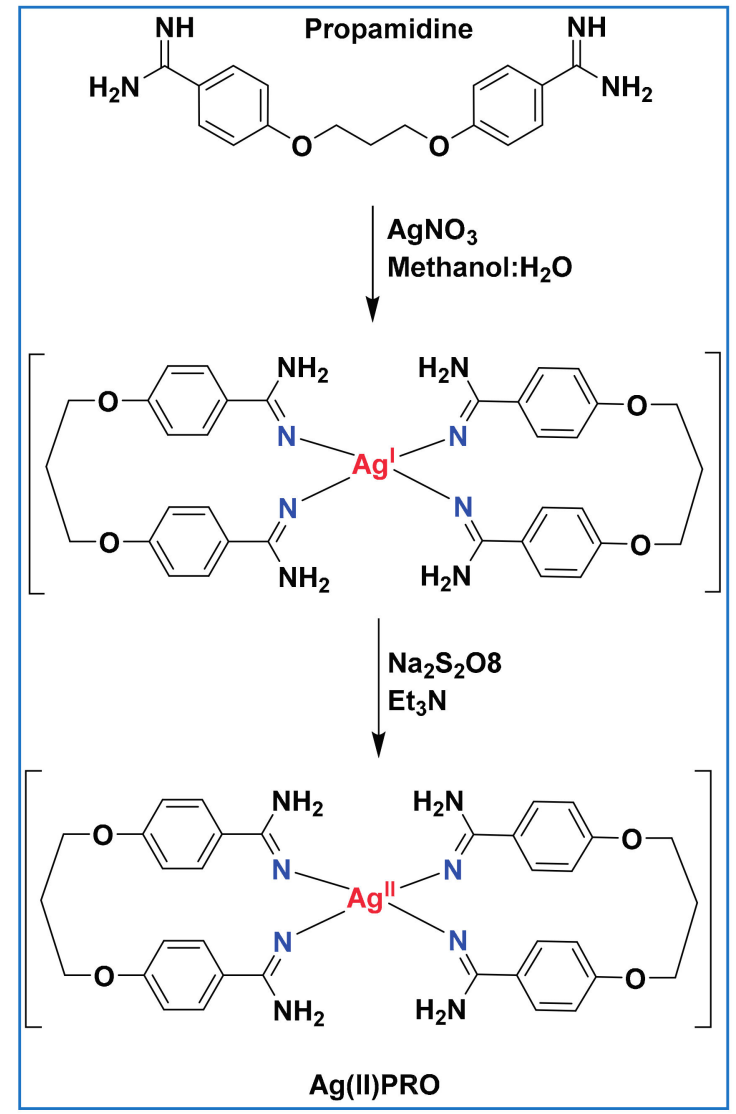

Figure 1. Synthetic scheme for the preparation of silver(II) propamidine complex.

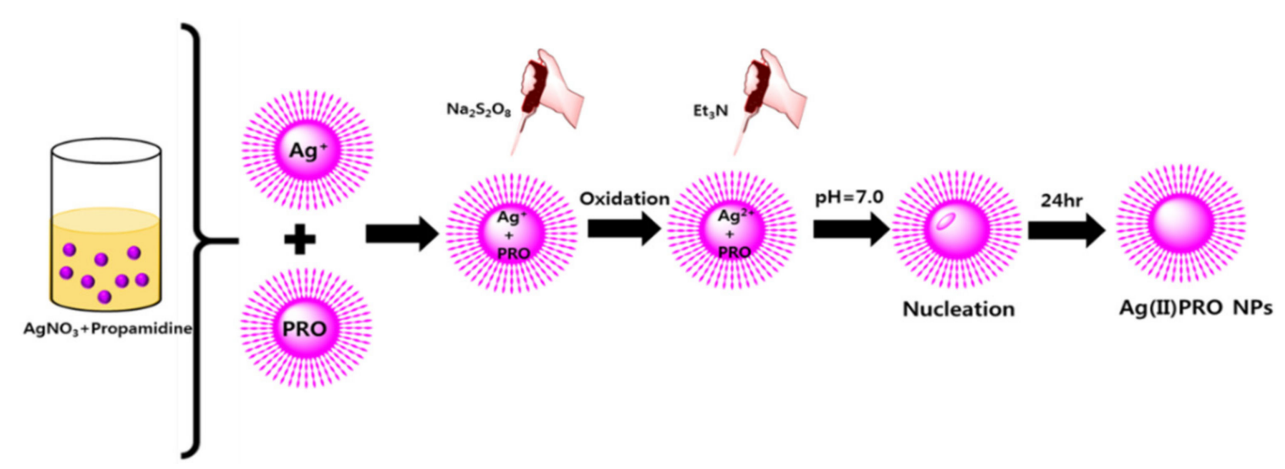

Figure 2. Schematic representation of the synthesis of silver(II) propamidine nanoparticles by reverse microemulsion technique. 
Microemulsions are defined as a clear, thermodynamically stable, mixture of liquid phases (oil and water) and surfactant, frequently in combination with a co-surfactant. Surfactant is usually a chemical compound possessing both hydrophilic and lipophilic properties. The three key reaction steps were involved in the formation of $\mathrm{Ag}$ (II)PRO nanoparticles in microemulsion technique. Firstly, we have to make the ligand propamidine water soluble. The commercially available propamidine is not completely soluble in heptane-water system (oil-water). To overcome this solubility issue, we have added diluted sulfuric acid to dissolve the propamidine ligand $(\mathrm{pH}>5)$ by forming the dihydrogensulfate salt of propamidine. The second step involves the oxidation of silver ion to high-valence silver complex by sodium peroxysulfate oxidation. Finally, trimethylamine was added for complexation reaction in a neutral homogenous microemulsion medium. This appropriate medium was maintained for $24 \mathrm{~h}$ at neutral condition $(\mathrm{pH}=7.0)$ to achieve fine and uniform sized nanoparticles.

The ${ }^{1} \mathrm{H}-\mathrm{NMR}$, FT-IR, and Q-TOF mass spectra were obtained to verify the formation of $\mathrm{Ag}(\mathrm{II}) \mathrm{PRO}$ complex. The disappearance of broad -NH band in IR and the absence of imine protons in NMR spectra of $\mathrm{Ag}(\mathrm{II}) \mathrm{PRO}$ complex clearly confirmed the coordination of the silver metal to propamidine ligand (Figure S1). In this study, XPS spectra was obtained to confirm the oxidation state of the silver atom in silver propamidine complex. XPS is one of the most widely used surface analysis technique to confirm the valence state of the atom in the synthesized products or compounds. Figure 3 shows XPS spectrum of high-valence silver propamidine complex. The Ag $3 \mathrm{~d}_{3 / 2}$ and $\mathrm{Ag} 3 \mathrm{~d}_{5 / 2} \mathrm{XPS}$ peaks were observed at $373.40 \mathrm{eV}$ and $367.90 \mathrm{eV}$, respectively, this was confirmed with literature values for $\mathrm{Ag}^{2+}$. We have synthesized the high-valence $\mathrm{Ag}(\mathrm{II}) \mathrm{PRO}$ nanoparticles by a previously published method from our group [20,21]. The $20 \mathrm{~nm}$ size of the Ag(II)PRO nanoparticles was achieved by altering the water-to-surfactant molar ratio (R). The microemulsion composition containing a ternary system of water/AOT/heptane with $\mathrm{R}=10$, the weight ratio of microemulsion composition should be 2.4/6.0/91.6 (water/AOT/heptane). The freshly synthesized Ag(II)PRO chemical and high-valence silver nanoparticles was shown in Figure S2a. The shape and size of the Ag(II)PRO nanoparticles were confirmed by TEM and particle size distribution which are shown in Figure S2b and Figure $4 \mathrm{~b}$. These studies confirmed that the synthesized Ag(II)PRO nanoparticles size were $20 \mathrm{~nm}$. The universally accepted method UV-Vis absorption spectroscopy is used to confirm the Ag(II)PRO nanoparticles and it showed strong absorption peak at $270 \mathrm{~nm}$ with characteristic peaks at $320 \mathrm{~nm}$ as shoulder peak (Figure 4a). The absorption pattern of $\mathrm{Ag}(\mathrm{II}) \mathrm{PRO}$ nanoparticles is different from the starting material propamidine ligand. The stability of the synthesized Ag(II)PRO nanoparticles was also confirmed by the UV-Vis spectroscopy. There was no significance difference between the freshly synthesized Ag(II)PRO nanoparticles and one-month aged nanoparticles stored under room temperature conditions.

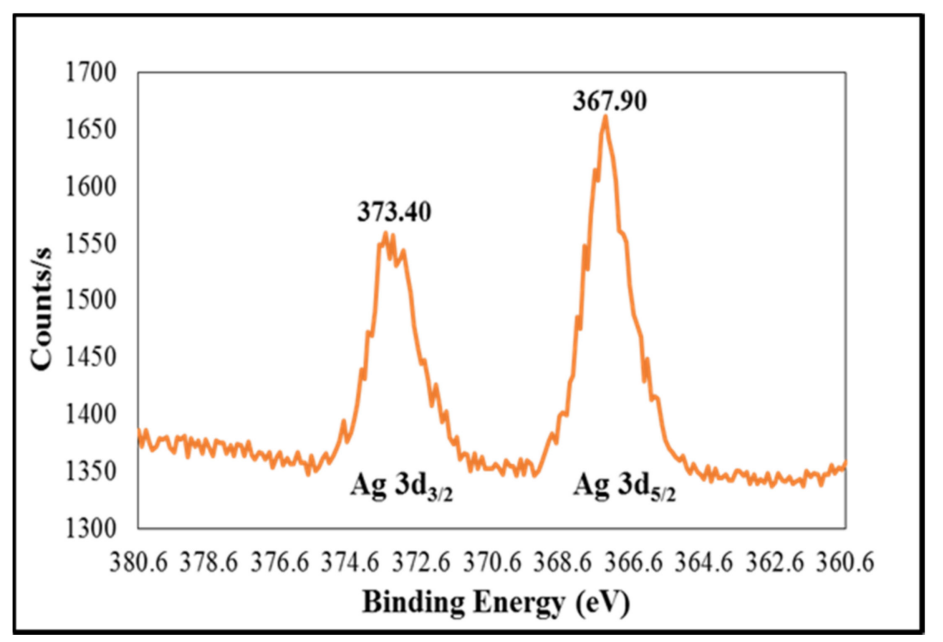

Figure 3. XPS (X-ray Photoelectron Spectroscopy) spectrum of the high-valence Ag(II)PRO complex. 
To compare the antibacterial activity we have prepared silver nanoparticles (AgNP) by using co-reduction method to get the $20 \mathrm{~nm}$ size of the silver nanoparticles [28]. The co-reduction method typically involves the two different reducing agents, sodium borohydrate used as primary reducing agent and trisodium citrate used as secondary reducing agent. It also serves as the stabilizing agent for the nanoparticles. The reduction was achieved at two different temperature conditions during silver nanoparticles synthesis. In this method, we have mixed required volume of sodium borohydrate and trisodium citrate in conical flask and heated to $60^{\circ} \mathrm{C}$ for $30 \mathrm{~min}$ with vigorous stirring. After $30 \mathrm{~min}$ the aqueous solution of silver nitrate was added dropwise to the mixture and temperature was increased to $90{ }^{\circ} \mathrm{C}$. Then the $\mathrm{pH}$ was adjusted to 10.5 by using $0.1 \mathrm{M}$ sodium hydroxide. The stirring was continued until the color was changed to yellow which indicated that the silver nanoparticles are formed (Figure S2c). As shown in Figure 4c, UV-Vis spectroscopy exhibits a sharp absorption peak at $398 \mathrm{~nm}$ wavelength corresponds to $20 \mathrm{~nm}$ size of silver nanoparticles. The size and morphology of AgNPs were confirmed by TEM (Figure S2d and Figure 4d). In this case, the particle size of $20 \mathrm{~nm}$ silver nanoparticles were synthesized and compared the antibacterial activity with similar size $(20 \mathrm{~nm})$ of the $\mathrm{Ag}(\mathrm{II}) \mathrm{PRO}$ nanoparticles.

a)

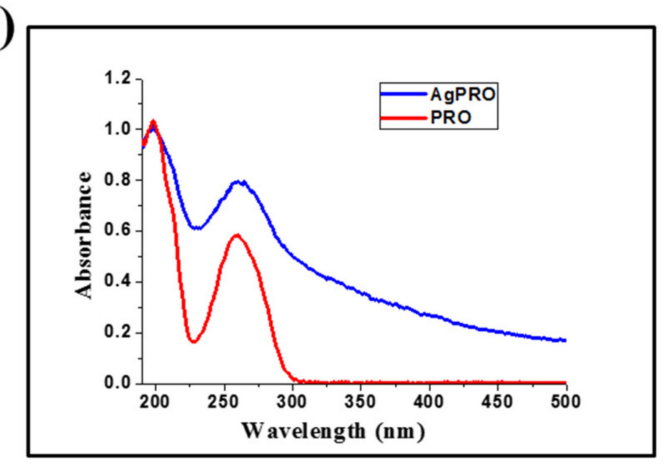

c)

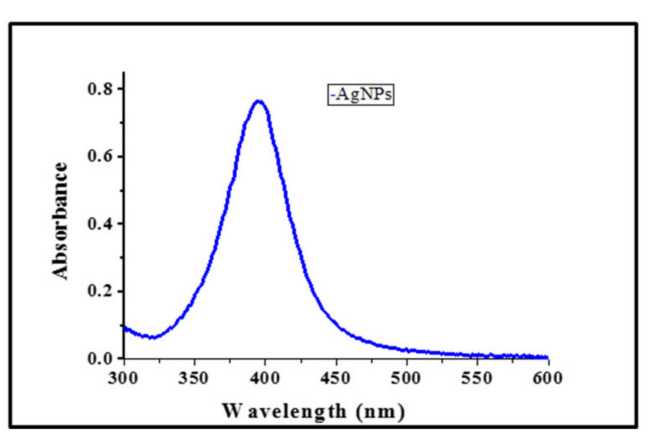

b)

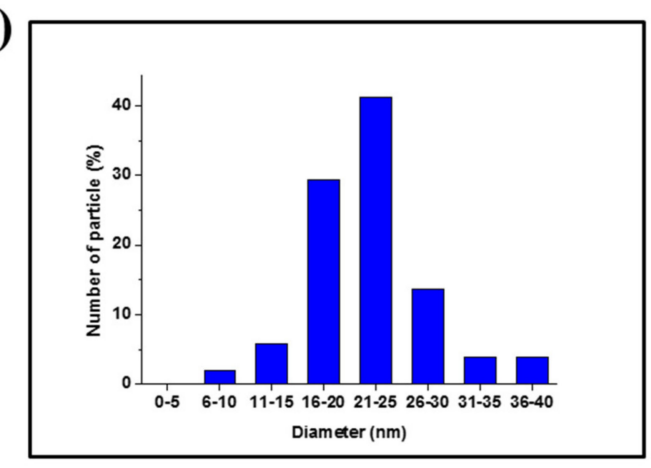

d)

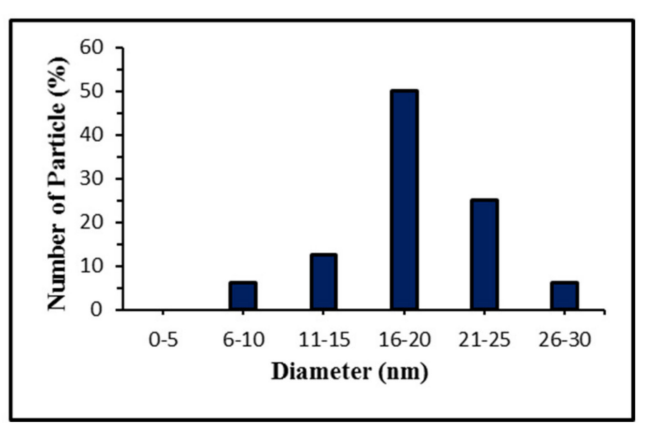

Figure 4. UV-Vis absorption spectra and particle size distribution of $\mathrm{Ag}(\mathrm{II}) \mathrm{PRO}$ nanoparticle $(\mathbf{a}, \mathbf{b})$ and $\operatorname{AgNPs}(\mathbf{c}, \mathbf{d})$.

\subsection{Antibacterial Activities of $A g(I I) P R O$ Nanoparticles and AgNPs (Comparative Study)}

The antibacterial activities of the silver nanoparticles depends on the valence form of the silver ion. Here, we have synthesized high-valence silver nanoparticles and compared the antibacterial activity with zero-valence silver nanoparticles with similar particle size. The TEM and size distribution study confirmed that the both nanoparticles were in same size $(\sim 20 \mathrm{~nm})$. The antibacterial activities of the synthesized Ag(II)PRO nanoparticles and AgNPs with similar size were tested against Gram-positive and Gram-negative strains responsible for DFU. Antibacterial activity mainly depends on the size and shape of the nanoparticles. Earlier reports suggested that small nanoparticles in size can enter bacterial cell membrane and prevent its natural metabolism processes [28,29]. It is observed that the antibacterial activity of $\mathrm{AgCHX}$ nanoparticles is far superior to the newly synthesized $\mathrm{Ag}$ (II)PRO nanoparticles. This is due to the presence of halogen element (chlorine) in fourth position of phenyl 
moiety of CHX. The halogenated polydiguanide compounds usually show higher bacteriostatic effect against Gram-positive and Gram strains [23]. The antibacterial activity of AgCHX nanoparticles was compared with $\mathrm{AgNO}_{3}$ and the gold standard wound healing agent silver sulfadiazine. In the present work, we have compared the antibacterial activity of Ag(II)PRO nanoparticles with AgNPs of similar size.

The bacteriostatic activity of synthesized nanoparticles were determined by MIC technique. The MICs and MBCs values of the $\mathrm{Ag}(\mathrm{II}) \mathrm{PRO}$ and AgNPs were determined by using agar dilution method and the antibacterial activity of these compound was compared in Table 1. MBCs of Ag(II)PRO nanoparticles with different bacterial strains were shown in Figure S3. From the obtained data, the synthesized $\mathrm{Ag}(\mathrm{II}) \mathrm{PRO}$ nanoparticles has the maximum antibacterial effect against all the tested strains than silver nanoparticles alone. MBCs of AgNPs with different bacterial strains were shown in Figure S4. The MICs of Ag(II)PRO were in the range of $6.25 \mu \mathrm{M}$, although the MBCs of $\mathrm{Ag}$ (II)PRO showed $6.25 \mu \mathrm{M}$. The Ag(II)PRO nanoparticles showed better antibacterial activity than the silver nanoparticles even at very low concentrations. The study showed that MIC of E. faecalis and S. aureus as Gram-positive bacteria is around $6.25 \mu \mathrm{M}$. These results indicated that there was no difference in MICs in terms of Gram-positive and Gram-negative bacteria. From the obtained data, the Ag(II)PRO nanoparticles showed antibacterial activity six times higher than AgNPs.

Table 1. MICs (minimal inhibitory concentrations) and MBCs (minimum bacterial concentrations) of synthesized high-valence Ag(II)PRO nanoparticles and AgNPs in broth dilution method.

\begin{tabular}{ccccc}
\hline \multirow{2}{*}{ Bacterial Strains } & \multicolumn{2}{c}{ AgNPs } & \multicolumn{2}{c}{ Ag(II)PRO NPs } \\
\cline { 2 - 5 } & $\mathbf{M I C}(\mu \mathbf{M})$ & $\mathbf{M B C}(\mu \mathbf{M})$ & MIC $(\mu \mathbf{M})$ & MBC $(\mu \mathbf{M})$ \\
\hline Pseudomonas aeruginosa & 20 & 60 & 6.25 & 12.5 \\
Staphylococcus aureus & 40 & 80 & 6.25 & 6.25 \\
Acinetobacter calcoaceticus & 40 & 80 & 6.25 & 6.25 \\
Enterococcus faecalis & 20 & 60 & 6.25 & 6.25 \\
Klebsiella pneumonia & 20 & 60 & 6.25 & 6.25 \\
Streptococcus agalactiae & 40 & 60 & 6.25 & 6.25 \\
\hline
\end{tabular}

\section{Conclusions}

The high-valence Ag(II)PRO nanoparticles and AgNPs were synthesized with similar size and characterized by spectroscopic methods. The antibacterial efficacies of both the nanoparticles were tested against three Gram-positive and Gram-negative strains responsible for DFU. The newly synthesized high-valence $\mathrm{Ag}(\mathrm{II}) \mathrm{PRO}$ nanoparticles showed higher antibacterial activity compared to silver-only nanoparticles (AgNPs). The MICs of synthesized Ag(II)PRO nanoparticles were much lower than the AgNPs. Due to their stability, high monodispersity, and higher antibacterial properties, $\mathrm{Ag}(\mathrm{II}) \mathrm{PRO}$ nanoparticles are expected to be the next generation topical agents for diabetic wounds.

Supplementary Materials: The following are available online at http:/ /www.mdpi.com/2076-3417/7/7/736/s1. Figure S1: ${ }^{1} \mathrm{H}$ NMR and FT-IR spectra of the propamidine (a) and newly synthesized silver(II) propamidine complex (b); Figure S2: Visual observation of freshly synthesized Ag(II)PRO nanoparticles (a) and AgNPs (c) TEM image of Ag(II)PRO nanoparticles (b) and AgNPs (d); Figure S3: Petri dishes initially supplemented with $10^{7} \mathrm{CFU} / \mathrm{mL}$ of Gram-positive/negative strains $(\mathrm{a}, \mathrm{b}, \mathrm{c}, \mathrm{d}, \mathrm{e}, \mathrm{f})$ and incubated with different concentrations of silver(II) propamidine nanoparticles, from left to right 1.5, 3, 6.25, 12.5, and $25 \mu \mathrm{M}$; Figure S4: Petri dishes initially supplemented with $10^{7} \mathrm{CFU} / \mathrm{mL}$ of Gram-positive/negative strains (a, b, c, d, e, f) and incubated with different concentrations of silver nanoparticles, from left to right control, 20, 40, 60, and $80 \mu \mathrm{M}$.

Acknowledgments: This work was supported by National Research Foundation of Korea (NRF) grant funded by the Ministry of Education, Science and Technology (MEST) (2015R1A2A1A05001842 and 2016R1A4A1010796). We are grateful to the Research Institute of Pharmaceutical Sciences at Seoul National University for providing experimental equipment and in vitro assay facility. 
Author Contributions: Joon Myong Song conceived and designed the experiments; Jinran Lee, Baskaran Purushothaman and Li Zhao performed the experiments; Joon Myong Song, Jinran Lee, Baskaran Purushothaman and Goutam Kulsi analyzed the data; Joon Myong Song, Jinran Lee, Baskaran Purushothaman and Goutam Kulsi wrote the paper.

Conflicts of Interest: The authors declare no conflict of interest.

\section{References}

1. Gariani, K.; Ugkay, I.; Lipsky, B.A. Managing diabetic foot infections: A review of the new guidelines. Acta Chir. Belg. 2014, 114, 7-16. [PubMed]

2. Sinwar, P.D. The diabetic foot management-Recent advance. Int. J. Surg. 2015, 15, 27-30. [CrossRef] [PubMed]

3. Lipsky, B.A.; Berendt, A.R.; Cornia, P.B.; Pile, J.C.; Peters, E.J.; Armstrong, D.G.; Deery, H.G.; Embil, J.M.; Joseph, W.S.; Karchmer, A.W.; et al. Infectious diseases society of america clinical practice guideline for the diagnosis and treatment of diabetic foot infections. Clin. Infect. Dis. 2012, 54, 132-173. [CrossRef] [PubMed]

4. Lipsky, B.A. Treating diabetic foot osteomyelitis primarily with surgery or antibiotics: Have we answered the question? Diabetes Care 2014, 37, 593-595. [CrossRef] [PubMed]

5. Citron, D.M.; Goldstein, E.J.; Merriam, C.V.; Lipsky, B.A.; Abramson, M.A. Bacteriology of moderate-to-severe diabetic foot infections and in vitro activity of antimicrobial agents. J. Clin. Microbiol. 2007, 45, 2819-2828. [CrossRef] [PubMed]

6. Rastogi, A.; Sukumar, S.; Hajela, A.; Mukherjee, S.; Dutta, P.; Bhadada, S.K.; Bhansali, A. The microbiology of diabetic foot infections in patients recently treated with antibiotic therapy: A prospective study from India. J. Diabetes Its Complicat. 2017, 31, 407-412. [CrossRef] [PubMed]

7. Shankar, E.M.; Mohan, V.; Premalatha, G.; Srinivasan, R.S.; Usha, A.R. Bacterial etiology of diabetic foot infections in South India. Eur. J. Intern. Med. 2005, 16, 567-570. [CrossRef] [PubMed]

8. Viswanathan, V.; Jasmine, J.J.; Snehalatha, C.; Ramachandran, A. Prevalence of pathogens in diabetic foot infection in South Indian type 2 diabetic patients. J. Assoc. Physicians India 2002, 50, 1013-1016. [PubMed]

9. Atiyeh, B.S.; Costagliola, M.; Hayek, S.N.; Dibo, S.A. Effect of silver on burn wound infection control and healing: Review of the literature. Burns 2007, 33, 139-148. [CrossRef] [PubMed]

10. Marx, D.E.; Barillo, D.J. Silver in medicine: The basic science. Burns 2014, 40, 9-18. [CrossRef] [PubMed]

11. Xiu, Z.M.; Zhang, Q.B.; Puppala, H.L.; Colvin, V.L.; Alvarez, P.J. Negligible particle-specific antibacterial activity of silver nanoparticles. Nano Lett. 2012, 8, 4271-4275. [CrossRef] [PubMed]

12. Franci, G.; Falanga, A.; Galdiero, S.; Palomba, L.; Rai, M.; Morelli, G.; Galdiero, M. Silver nanoparticles as potential antibacterial agents. Molecules 2015, 20, 8856-8874. [CrossRef] [PubMed]

13. Pham, X.H.; Shim, S.; Kim, T.H.; Hahm, E.; Kim, H.M.; Rho, W.Y.; Jeong, D.H.; Lee, Y.S.; Jun, B.H. Glucose detection using 4-mercaptophenyl boronic acid-incorporated silver nanoparticles-embedded silica-coated graphene oxide as a SERS substrate. BioChip J. 2017, 11, 46-56. [CrossRef]

14. Zhu, L.; Guo, D.; Sun, L.; Huang, Z.; Zhang, X.; Ma, W.; Wu, J.; Xiao, L.; Zhao, Y.; Gu, N. Activation of autophagy by elevated reactive oxygen species rather than released silver ions promotes cytotoxicity of polyvinylpyrrolidone-coated silver nanoparticles in hematopoietic cells. Nanoscale 2017, 9, 5489-5498. [CrossRef] [PubMed]

15. Shahi, S.K.; Kumar, A. Isolation and genetic analysis of multidrug resistant bacteria from diabetic foot ulcers. Front. Microbiol. 2015, 6. [CrossRef] [PubMed]

16. Rai, M.K.; Deshmukh, S.D.; Ingle, A.P.; Gade, A.K. Silver nanoparticles: The powerful nanoweapon against multidrug-resistant bacteria. J. Appl. Microbiol. 2012, 112, 841-852. [CrossRef] [PubMed]

17. Kim, K.S.; Lee, J.Y.; Kwon, S.Y.; Yang, H.J.; Choi, E.K.; Shin, M.H.; Ahn, K.S.; Um, J.Y.; Lee, J.H.; Jang, H.J. Comparative transcriptomic analysis of the multi-targeted effects of the herbal extracts against Escherichia coli O157:H7. BioChip J. 2012, 6, 379-390. [CrossRef]

18. Yang, K.; Liu, J.; Shi, H.G.; Zhang, W.; Qu, W.; Wang, G.X.; Wang, P.L.; Ji, J.H. Electron transfer driven highly valent silver for chronic wound treatment. J. Mater. Chem. B 2016, 4, 5729-5736. [CrossRef]

19. Dellasega, D.; Facibeni, A.; Di Fonzo, F.; Bogana, M.; Polissi, A.; Conti, C.; Ducati, C.; Casari, C.S.; Bassi, A.L.; Bottani, C.E. Nanostructured $\mathrm{Ag}_{4} \mathrm{O}_{4}$ films with enhanced antibacterial activity. Nanotechnology 2008, 19. [CrossRef] [PubMed] 
20. Zhao, J.; Zhang, W.; Wang, G. Inorganic Antibacterial Agents Containing High Valent Silver and Preparation Method Thereof. US Patent Application US 10/578,532, 27 October 2004.

21. Pal, S.; Yoon, E.J.; Tak, Y.K.; Choi, E.C.; Song, J.M. Synthesis of highly antibacterial nanocrystalline trivalent silver polydiguanide. J. Am. Chem. Soc. 2009, 131, 16147-16155. [CrossRef] [PubMed]

22. Rangasamy, S.; Tak, Y.K.; Kim, S.; Paul, A.; Song, J.M. Bifunctional therapeutic high-valence silver-pyridoxine nanoparticles with proliferative and antibacterial wound-healing activities. J. Biomed. Nanotechnol. 2016, 12, 182-196. [CrossRef] [PubMed]

23. Thrower, W.R.; Valentine, F.C. Propamidine in chronic wound sepsis: An experimental and clinical study. Lancet 1943, 241, 133-136. [CrossRef]

24. Wien, R.; Harrison, J.; Freeman, W.A. Diamidines as antibacterial compounds. Br. J. Pharmacol. Chemother. 1948, 3, 211-218. [CrossRef] [PubMed]

25. Bell, C.A.; Hall, J.E.; Kyle, D.E.; Grogl, M.; Ohemeng, K.A.; Allen, M.A.; Tidwell, R.R. Structure-activity relationships of analogs of pentamidine against plasmodium falciparum and leishmania mexicana amazonensis. Antimicrob. Agents Chemother. 1990, 34, 1381-1386. [CrossRef] [PubMed]

26. Donkor, I.O.; Clark, A.M. In vitro antimicrobial activity of aromatic diamidines and diimidazolines related to pentamidine. Eur. J. Med. Chem. 1999, 34, 639-643. [CrossRef]

27. Werbovetz, K. Diamidines as antitrypanosomal, antileishmanial and antimalarial agents. Curr. Opin. Investig. Drugs 2006, 2, 147-157.

28. Agnihotri, S.; Mukherji, S.; Mukherji, S. Size-controlled silver nanoparticles synthesized over the range 5-100 $\mathrm{nm}$ using the same protocol and their antibacterial efficacy. RSC Adv. 2014, 4, 3974-3983. [CrossRef]

29. Pal, S.; Tak, Y.K.; Song, J.M. Does the antibacterial activity of silver nanoparticles depend on the shape of the nanoparticle? A study of the gram-negative bacterium Escherichia coli. Appl. Environ. Microbiol. 2007, 73, 1712-1720. [CrossRef] [PubMed]

(C) 2017 by the authors. Licensee MDPI, Basel, Switzerland. This article is an open access article distributed under the terms and conditions of the Creative Commons Attribution (CC BY) license (http:/ / creativecommons.org/licenses/by/4.0/). 